\title{
Recent Aspects in the Genetic Renal Mechanisms Involved in Hypertension
}

\author{
Takeo SATOH, Shigeru Owada and Masashi IsHIDA
}

\begin{abstract}
The kidney plays an important role in the blood pressure regulation primarily by modulating tubular sodium reabsorption. Various hormones, vasoactive peptides, autacoids and transporters or channels in renal tubules are involved in this process. Genes associated with renal tubular sodium handling are possibly related to the development of hypertension. Genes of the renin-angiotensin-aldosterone system are thought to be especially important as causal genes of hypertension. Na-K-ATPase, biochemically equal to Na pump, exists on the basolateral membrane of renal epithelial cells. It plays a central role in $\mathrm{Na}$ reabsorption and creates a driving force for transepithelial transport. Na-K-ATPase activity is regulated by adducin, a membrane-bound skeletal protein, as well as by several hormones such as dopamine, endogenous ouabain-like factor or cytochrome P450 metabolites. Genes of these factors involved in Na-K-ATPase regulation should be related to the development of hypertension. The endothelin system, atrial natriuretic peptide and nitric oxide regulate the tonus of blood vessels as well as renal sodium excretion. Several reports have indicated that genes of these substances are crucial in the pathogenesis of hypertension.
\end{abstract}

(Internal Medicine 38: 919-926, 1999)

Key words: kidney, hypertension, gene

\section{Introduction}

The physiological and biochemical processes of no single organ can account for the mechanisms of blood pressure regulation. Hence genetic abnormalities causing the malfunction of any of the organs involved may contribute to the development of hypertension. Among these organs the kidney is of central importance, as shown through physiological, biochemical, pharmacological, as well as recent genetic investigations. Since essential hypertension, which is most of human hypertension, is primarily a polygenic disease and is subject to modification by environmental factors, the identification of a causal gene has proved difficult. In contrast, the candidate gene in experimental hypertensive rats has been elucidated by the candidate gene approach as well as by genomic screening method because the rat causal gene is homogenous. This review is an outline of the recent achievements in elucidating the genetic renal factors involved in the development of hypertension, both in experimental models and in humans.

\section{Renin-Angiotensin-Aldosterone System}

The renin-angiotensin-aldosterone system regulates the water and electrolyte balance, effective circulating blood volume and blood pressure by synthesizing angiotensin II, a potent vasoactive peptide, and aldosterone. The relationship between polymorphism of genes associated with this system and the development of hypertension has been studied extensively in recent years. The positive results supporting the association of this system with hypertension are summarized in Table 1.

\section{Renin}

The regulation of expression of the renin gene is tissue and organ specific, the major tissue involved in the production of renin being the juxtaglomerular apparatus of the kidney. A restriction fragment length polymorphism (RFLP) in the renin gene was found between Dahl salt-sensitive and Dahl salt-resistant rats (1). In contrast, no evidence was observed in the renin genotype-dependent phenotypic difference in the reninangiotensin system that could account for the effect of the renin locus on blood pressure in Lyon rats (2). Further investiga-

From Division of Nephrology and Hypertension, Department of Medicine, St. Marianna University School of Medicine, Kawasaki

Reprint requests should be addressed to Dr. Takeo Satoh, Division of Nephrology and Hypertension, Department of Medicine, St. Marianna University School of Medicine, 2-16-1 Sugao, Miyamae-ku, Kawasaki, Kanagawa 216-8511 
Table 1. Proposed Genes of Renin-Angiotensin-Aldosterone System Associated with Hypertension

\begin{tabular}{ll}
\hline Gene and method to prove & Model of hypertension \\
\hline $\begin{array}{l}\text { Renin } \\
\text { Restriction fragment length polymorphism (RFLP) }\end{array}$ & $\begin{array}{l}\text { Dahl salt-sensitive rat } \\
\text { Transgenic rat }\end{array}$ \\
High human renin hypertension by producing transgenic strain & \\
Angiotensinogen (AGT) & Mice \\
$\quad$ Direct association of the AGT gene polymorphism and blood pressure & SHR \\
Tissue AGT expression & Human hypertension \\
T174M or M235T phenotypic polymorphism & \\
Angiotensin-converting enzyme (ACE) & SHR \\
Strong association of blood pressure with QTL & \\
$\quad$ that are close to the ACE locus on chromosome 10 & Human hypertension \\
An insertion/deletion polymorphism & \\
Angiotensin II receptors & \\
Close relationship between expression of AT1 receptor and hypertension & Knockout mouse \\
& SHR using AT1 receptor \\
T573C, A1062G, A1166C, G1571T or A1878G variant & Antisense \\
\hline
\end{tabular}

QTL: quantitative trait loci.

tions are necessary to prove the genetic co-segregation between a polymorphism of the renin gene and hypertension. Interestingly, a recent examination using a model of spontaneously high human renin hypertension in the rat by producing two transgenic strains, one for human angiotensinogen and the other for human renin, both with endogenous promoters, showed that neither transgenic strain was hypertensive. These strains were crossed, however, yielding offspring with leading to death after a mean of 55 days if left untreated. These observations suggest that this double transgenic strain will facilitate the simultaneous investigation of genetic and pathophysiological aspects of renin-induced hypertension (3).

\section{Angiotensinogen}

\section{Evidence in experimental models}

The genetic linkage between the angiotensinogen (AGT) gene and hypertension has also been investigated using experimental models. Kim et al (4) proved the direct association between genotypes at the AGT locus and blood pressure using mice carrying zero, one, three or four functional copies of the murine wild-type AGT gene at its normal chromosome location. In the investigation using hypertensive rats, the AGT locus in spontaneously hypertensive rat (SHR) cosegregated with a specific increase in blood pressure (5). Furthermore, the functional significance of tissue angiotensinogen has been elucidated in SHR. The expression of tissue AGT is regulated differently in SHR and its corresponding normotensive control, the Wistar Kyoto (WKY) rat, and the development of hypertension is associated at least temporarily with increases in cardiac and adipogenic AGT mRNA in SHR (6). The transfection of antisense oligonucleotides against rat AGT results in a transient decrease in the high blood pressure of SHR accompanied by a decrease both in hepatic AGT mRNA and in plasma angiotensin II levels (7).

\section{Evidence in human hypertension}

The evidence supporting a genetic linkage between AGT and hypertension in Caucasian subjects was firstly presented by Jeunemaitre et al in 1992 who demonstrated that T174M and M235T variants on exon 2 of the AGT gene are associated with the development of hypertension (8). M235T polymorphism showed an especially close correlation to the blood AGT concentration, and to the severity of hypertension. A similar linkage between M235T variant and human hypertension was observed in Africans (9) and in Japanese (10) subjects. However, Caulfield et al reported that there was no association between T174M or M235T polymorphism and essential hypertension (11). Therefore in conclusion it can be stated that although the AGT gene could be one of the important causal genes of essential hypertension, how mutations in this region opposed to T174M and M235T polymorphisms may result in hypertension remains to be determined.

\section{Angiotensin-Converting Enzyme}

\section{Evidence in experimental models}

The first evidence for the association of angiotensin-converting enzyme (ACE) locus and hypertension in experimental model rats was presented by the wide genomic scanning of the F2 generation (spontaneously hypertensive rat-stroke prone $($ SHRSP $) \times W K Y)$ by two groups $(12,13)$. Both reports indi- 
cate a strong association of blood pressure with the quantitative trait loci (QTL) which are close to the ACE locus on chromosome 10. However, recent reports have denied the association of the ACE gene and hypertension in experimental models. Experiments in which the cDNAs for the WKY and SHRSP were cloned and characterized indicate that an alteration of the primary structure of the rat ACE does not contribute to hypertension in the SHRSP (14). The crossbreeding experiment between SHRSP and a congenic reference strain showed that a molecular variant of the ACE gene determines plasma ACE activity but exhibits no direct effect on blood pressure (15). Furthermore, although ACE gene polymorphisms were associated with the plasma ACE concentration, no linkage was observed between ACE gene variant and blood pressure (16).

\section{Evidence in human hypertension}

An insertion/deletion (I/D) polymorphism of ACE located in intron 16 has a substantial effect on plasma ACE levels (17). The deletion (D) allele is associated with an increased plasma ACE concentration in normal individuals. The plasma ACE concentration is the highest in subjects with D/D genotype, followed by those with I/D genotype, and the lowest in those with $\mathrm{I} / \mathrm{I}$ genotype. However, results concerning the association between this ACE polymorphism with blood pressure in the human are controversial. Several studies revealed negative (1820), with fewer studies showing a positive correlation (21). Though the reason of these differing results is not yet well understood, Abbud et al (22) showed that a significant association was detected between hypertension and D/D genotype of the ACE gene when the relation was adjusted for age, sex, and body mass index. Racial differences may also contribute to the inconsistency of these results. Interestingly, a recent report examining the interaction between I/D of ACE gene and M235T AGT gene polymorphic alleles has proved that the interaction of the I/D ACE and M235T AGT polymorphic alleles can contribute to essential hypertension, despite the absence of single gene associations with the condition (23). A recent report in Japanese has suggested an association with the ACE gene and the heterogeneous process of salt sensitivity in essential hypertension (24).

\section{Angiotensin II Receptors}

\section{Evidence in experimental models}

Angiotensin II (AII) is synthesized via ACE as well as kimase, one of the serin protease that generates AII independent of ACE. The AII receptors are classified into two subtypes, AT1 and AT2. The correlation between the AT1 gene and blood pressure regulation has recently been investigated. Investigations in which the mouse gene encoding AT1 receptor is disrupted by gene targeting, demonstrate that AT1 receptor function is required for vascular and hemodynamic responses to AII, and that altered expression of the AT1 receptor gene has marked effects on blood pressure (25). Studies using AT1 receptor antisense (AT1R-AS) reveal that an injection of AT1RAS results in a lowering of blood pressure in the spontane- ously hypertensive rats. The reduction of blood pressure is associated with the expression of the AT1R-AS transcript, as well as and decreases in the AT1 receptor of many peripheral AII target tissues including the kidney. These observations indicate that there is a close relationship between the expression of the AT1 receptor gene and blood pressure regulation in the spontaneously hypertensive rats (26).

\section{Evidence in human hypertension}

Bonnardeaux et al (27) identified the five polymorphisms of AT1 receptors (T573C, A1062G, A1166C, G1517T, and A1878G). A case-control study performed on white hypertensive and normotensive subjects using three of five polymorphisms showed a significant increase in the allele frequency of C1166 in hypertensive subjects but not in C573 or G1878. However, other recent reports failed to prove the association the C1166 polymorphism of the AT1 receptor gene with essential hypertension $(28,29)$. There was a tendency for hypertensive patients with a late age at diagnosis to have a decreased prevalence of the C1166 allele (29). A very recent study in Japanese people suggests the gene polymorphisms of both AT1 and AT2 receptors are not directly involved in the increase in genetic risk of hypertension, but that the AT1 receptor gene might contribute genetically to the increase of left ventricular mass (30). Further investigation will be necessary to address the association of the polymorphisms of AII receptor gene with hypertension.

\section{SA Gene}

\section{Evidence in experimental models}

The SA (subtractive clone A) gene maps onto rat chromosome 1 and encodes a protein of which the function is not understood. The expression of the SA gene in the kidney of SHR is greater than 10 -fold that observed in WKY rats. The blood pressure of F2 rats inheriting two SHR alleles of the SA gene is significantly higher than that of the F2 rats inheriting two WKY alleles. These observations indicate that the SA gene, or a gene closely linked to it, has the capacity to influence the blood pressure of the F2 rat population (31). In a study using stroke-prone SHR (SHRSP), the systolic blood pressure became elevated after sodium loading but not under basal conditions among groups of rats defined by zygosity at the SA locus, consistent with the hypertensive effect of the SHRSP allele. However, no effect of the SA genotype on diastolic pressure was observed (32). In situ hybridization of SHR and WKY rat kidney sections with a radioactive-labeled rat SA complementary DNA probe showed the increased signal in the SHR to be localized at the proximal tubule (33). Moreover, the distribution of the SA gene expression in the proximal tubule is in a strain-dependent manner; in the proximal convoluted tubule in Sprague Dawley rats; in the proximal straight tubule in the WKY; and along the entire proximal tubule in the SHR (34). Taken together, in the SHR, the SA gene expression is augmented in the proximal tubule especially after sodium loading. Although the physiological significance of this observation is 
not understood, it is possible that the increased SA gene expression in the proximal tubule may contribute in part to the sodium sensitivity of SHR. Interestingly, the $\beta$-subunit of the epithelial sodium channel gene is located close to the SA gene on rat chromosome 1 , involved in the inherited blood pressure control in the SHR and Dahl salt-sensitive rats (35).

\section{Evidence in human hypertension}

A few studies have investigated the association of the SA gene and human hypertension. Iwai et al (36) showed that the human SA gene mapped onto human chromosome 16 and that there were significant differences in the frequency of the A2 allele of the SA gene observed between the hypertensive and control groups in Japanese. This provides favorable evidence that the SA gene is a candidate gene for human essential hypertension. In contrast, a cross-sectional case-control study involving white individuals did not prove the association of the SA genotype with hypertension, but gave preliminary evidence for a possible association with variation in body mass index in a severely affected hypertensive group with a strong family history of hypertension (37). Further studies will be necessary to identify the universal role of the SA gene in human essential hypertension.

\section{Adducin}

\section{Evidence in experimental models}

An enhanced rate of sodium transport across the renal tubular cells contributes in part to the elevation of blood pressure in the Milan hypertensive strain (MHS), one of the genetically hypertensive model rats. This phenomenon is abolished by removing the membrane cytoskeleton. Na-K-ATPase activity in the proximal tubule in MHS is higher than that in its corresponding normotensive strain, Milan normotensive strain (MNS) (38), and this finding is thought to be one of the mechanisms causing faster sodium transport in MHS. The adducin heterodimer with alpha and beta subunits is a membrane-bound skeletal protein affecting the assembly of the actin-based cytoskeleton. Complementary DNA sequencing of alpha- and beta-adducin subunits of MHS led to the identification of a missense mutation in each subunit. Either subunit interacts epistatically and, when both hypertensive variants are present at the homozygous state in the same animal, they explain up to $50 \%$ of the blood pressure difference between MHS and MNS (39). Adducin is involved in the control of many cellular functions. It promotes binding between spectrin and actin in a calmodulin-dependent manner and may play a role in regulating the rate of ion transport across the plasma membrane. The MHS adducin variants affect actin assembly differently from MNS variants in vitro, as well as the localization of $\mathrm{aV}$ integrins in vivo in transfected rat renal tubular cells. They also increase the number of Na-K pump units exposed on the cell surface and their activity (40). These observations indicate that adducin plays a crucial role in the regulation of transepithelial sodium transport and contributes to the tubular sodium reabsorption responsible for hypertension in this strain.

\section{Evidence in human hypertension}

The association of adducin polymorphisms with human hypertension has been investigated in recent years. Linkage analysis in Caucasian populations reveals a significant association between an alpha-adducin polymorphism (Gly 460 Trp) and hypertension. Moreover, treatment with hydrochlorothiazide for two months causes a greater fall in the mean arterial blood pressure in hypertensive patients who are heterozygous for the mutant allele (Gly/Trp) than in wild-type homozygous (Gly/ Gly) hypertensive patients. These observations suggest that alpha-adducin is associated with a salt-sensitive form of essential hypertension (41). In contrast, a very recent report suggests that the alpha-adducin polymorphism (Gly $460 \mathrm{Trp}$ ) is unlikely to have a major effect on the susceptibility of the Japanese population to hypertension. However, this study does not exclude the involvement of alpha-adducin in the pathogenesis of hypertension because the 460Trp variant appears to be relatively common in the Japanese (54 to 60\%) compared with a reported prevalence of 13 to $23 \%$ in Caucasians (42).

\section{Epithelial Sodium Channel}

\section{Evidence in experimental models}

A hypothesis has been proposed that missense mutation or truncations of the epithelial sodium channel found in Liddle's syndrome might also contribute to common polygenic forms of hypertension. A study using SHRSP and WKY shows that in the rat, the beta- and gamma-subunits of the epithelial sodium channel, as in humans, are in close linkage; they map to rat chromosome 1 and cosegregate with systolic blood pressure following dietary intake of $\mathrm{NaCl}$. The alpha-subunit mapping on chromosome 4 has no effect on blood pressure. A comparative analysis of the complete coding sequences of all three subunits in the SHRSP and WKY reveals no biologically relevant mutations. Moreover, no differences are found in the mRNA levels of all three subunits in the kidneys of these strains. These observations do not support a crucial contribution of the epithelial sodium channel genes to blood pressure regulation in the polygenic hypertension of SHRSP (43).

\section{Evidence in human hypertension}

Liddle's syndrome (pseudoaldosteronism) is an autosomal dominant form of human hypertension characterized by early onset of hypertension, typically associated with hypokalemia, suppressed plasma rennin activity and low aldosterone concentration. Linkage studies in Liddle's original kindred demonstrate a linkage of this trait to a segment of human chromosome 16 that contains two candidate genes of interest, betaand gamma-subunits of the epithelial sodium channel. The investigation of these channel genes in Liddle's syndrome kindred reveals the mutations of the beta-subunit in each that results in the deletion of the normal cytoplasmic carboxyl terminus of the encoded protein (44). The expression of the epithelial sodium channels containing mutant beta- and gamma-subunits results in their constitutive activation (45). Another investigation of Liddle's syndrome in the Japanese demonstrated 
no mutation in the beta-subunit of the epithelial sodium channel, but the presence of a mutation truncating the cytoplasmic C-terminus of the gamma-subunit, suggesting the genetic heterogeneity of Liddle's syndrome (46).

\section{Na-K-ATPase}

Na-K-ATPase, biochemically equivalent to a sodium pump, is an integral membrane protein responsible for establishing the electrochemical gradient of sodium and potassium ions across the plasma membrane of mammalian cells. This enzyme activity or structure is regulated by adducin, the cytoskeletal protein which modulates the membrane structure as described earlier, as well as several hormones including dopamine, vasoactive peptide and cytochrome $\mathrm{P} 450$ metabolites. A genetic defect or disorder of adducin, the renal dopamine system or cytochrome $\mathrm{P} 450$ results in an elevation of blood pressure associated with enhanced renal tubular Na-K-ATPase activity (Fig. 1).

\section{Renal Dopamine System}

\section{Evidence in experimental models}

Dopamine plays an important role in the regulation of renal function. In addition to its well-known hemodynamic effects, dopamine produces a natriuresis through a direct action on the renal tubule, attributed in part to the inhibition of $\mathrm{Na}-\mathrm{K}$ -
ATPase in the renal epithelial cells. Dopamine inhibits Na-KATPase in the proximal tubule through complex intracellular signal transduction via its D1 receptor. The Dahl salt-sensitive rat and SHR, which have normal dopamine production and expression of dopamine receptors in the kidney, have a defect in the coupling of D1 receptor to the GS-protein/effector enzyme complex. A consequence of the defective D1 receptor/effector enzyme coupling is a decreased ability of D1 agonist to inhibit Na-K-ATPase activity causing the elevation of blood pressure (47). The D1 receptors in the kidney are classified into D1A, a major D1 receptor expressed in the renal proximal tubule, and D1B subtypes. The blood pressure in mice lacking functional D1A receptor is higher in homozygous and heterozygous mice than in normal controls, suggesting a causal relationship of the D1A receptor gene with hypertension (48).

\section{Evidence in human hypertension}

In contrast to the results in experimental hypertensive model rats, in human hypertension, it is not yet clarified whether the disorder of the renal dopamine system results in the elevation of blood pressure in relation to renal Na-K-ATPase. Hypertensive subjects; however, have less renal dopamine production for the amount of sodium ingested and a decreased renal dopamine production in response to a protein load as compared with normotensive subjects, consistent with a renal defect in conversion of DOPA to dopamine (49). Similarly, dopaminuric response to a high sodium diet is decreased in individuals with

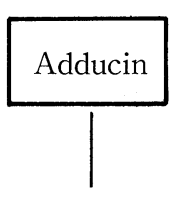

Missense mutation

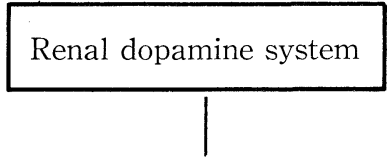

Defect in the coupling of dopamine receptor to GS-protein/effector enzyme complex

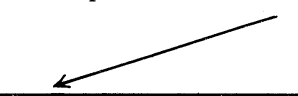

Enhancement of renal Na-K-ATPase activity

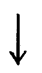

Enhancement of tubular $\mathrm{Na}$ reabsorption

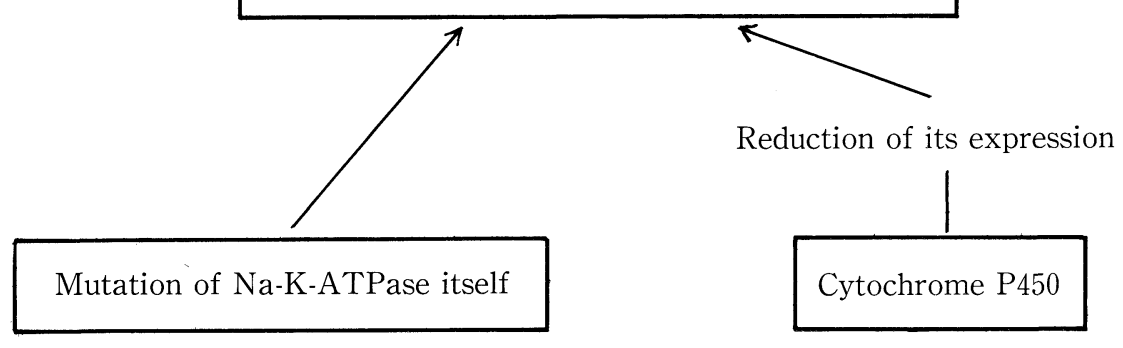

Figure 1. Genetic mechanisms of hypertension involving renal Na-K-ATPase activation. All mechanisms result in the enhancement of Na-K-ATPase activity and the subsequent increase of tubular sodium reabsorption. Finally sodium retention and hypertension develop. 
familial hypertension, suggesting the relationship between the renal dopaminergic defect and the development of hypertension (50). Further investigations will be necessary to prove that the renal dopaminergic defect in human hypertension involves an alteration in the renal $\mathrm{Na}-\mathrm{K}$-ATPase.

\section{Ouabain-Like Factor}

\section{Evidence in experimental models}

The amount of OLF in tissue from Milan hypertensive strain is higher than that from Milan normotensive strain, suggesting the role of OLF in the pathogenesis in MHS hypertension (51). Increased secretion of OLF may lead to elevated cytosolic $\mathrm{Ca}^{2+}$ and vasoconstriction, responsible for the development and perpetuation of hypertension. OLF has been thus thought to play important roles in long-term blood pressure control (52). A recent observation by Rayson demonstrated that a circulating $\mathrm{Na}^{+} / \mathrm{K}^{+}$-ATPase inhibitor may not be effective in eliciting chronic forms of hypertension unless the homeostatic response of the target cell is impaired, as apparent in the Dahl salt-sensitive rats (53).

\section{Evidence in human hypertension}

Accumulating evidence has suggested that several sodium pump inhibitors, similar to cardiotonic steroids, are present in the human body (54). Ouabain-like factor, the most appealing candidate, has been found to increase with high sodium intake and hypervolemia, as well as essential hypertension (55).

\section{Cytochrome P450}

Arachidonic acid is metabolized in the kidney by the cytochrome P450-dependent monooxygenase. These metabolites exert renal vasodilation and inhibition of tubular Na-K-ATPase activity, and are thought to be closely related to the pathogenesis of hypertension. The production of 20-HETE by P450 monooxygenase in the outer medulla of the kidney (56), as well as the expression of cytochrome P450 itself (57) is reduced in Dahl salt-sensitive rats (Fig. 1). Furthermore, the cytochrome P450 genotype cosegregates with hypertension in Dahl salt-sensitive rats. The $\mathrm{P} 450$ locus is located on rat chromosome 5 , where a quantitative trait locus for blood pressure has been detected (56).

\section{Other Genetic Factors which Affect Na-K-ATPase}

Na-K-ATPase is an enzyme composed of alpha and beta subunits, alpha being the catalytic subunit. The alpha subunit of Na-K-ATPase has three isoforms, alpha-1, -2 and -3 . The main isoform detected in the renal tubules is alpha-1. An adenine (A) 1079 to thymine (T) transversion, resulting in the substitution of glutamine at position 276 with leucine. This is associated with decreased net ${ }^{86} \mathrm{Rb}^{+}$uptake exerted by Na-KATPase in the Dahl salt-sensitive rats, suggesting a putative role of this enzyme in the pathogenesis of hypertension (58).

\section{Endothelin}

The endothelin system, consisting of a series of potent vasoconstrictive peptides and their receptors, is potentially important in the regulation of blood pressure. The gene coding for endothelin-2 (ET-2) (59) and ET-3 (60) that are located on chromosome 5 and on chromosome 3 , respectively, cosegregate strongly with systolic blood pressure in the Dahl salt-sensitive rats. Moreover, the augmentation of gene expression of endothelin converting enzyme-1 (ECE-1), an enzyme that synthesizes bioactive ET-1 in the nephron, may contribute to the development of hypertension through the increase in ET-1 synthesis resulting in the enhancement of sodium retention in the kidney in SHR (61). The endothelin receptors are classified into ETA and ETB subtypes. In the renal cortex from SHR, the ratio of ETA to ETB diminishes compared with that from the normotensive SD rats. The affinity of ET receptors in SHR is also higher than that in SD rats. These observations indicate the distribution and functional roles of ETA and ETB receptors in the pathogenesis of hypertension in SHR (62).

\section{Atrial Natriuretic Factor or Peptide}

Atrial natriuretic factor (ANF) or peptide (ANP) exerts multiple potent antihypertensive actions via its receptor and guanylate cyclase. ANF exhibits vasodilation, suppression of plasma renin activity, inhibition of the synthesis and release of aldosterone, and promotes diuresis and natriuresis. In experimental models, ANP knockout mice develop salt-sensitive hypertension $(63,64)$ in part due to their inability to reduce plasma renin activity (64). On the other hand, disruption of the guanylate cyclase-A gene results in salt-resistant hypertension in mice (65). In human hypertension, mutations in the ANP gene are observed more prominently among African hypertensive individuals (66).

\section{Nitric Oxide and Its Synthase}

Nitric oxide (NO) produced by nitric oxide synthase (NOS) plays a significant role in the regulation of systemic and renal hemodynamics and sodium excretion. Alles of the inducible NOS (iNOS) that map on rat chromosome 10 cosegregate with the blood pressure in SHR (67). A disruption of the endothelial NOS (eNOS) in mice results in hypertension, indicating that eNOS mediates basal vasodilation (68). In the Sabra salt-sensitive $(\mathrm{SBH} / \mathrm{y})$ and Sabra salt-resistant $(\mathrm{SBN} / \mathrm{y})$ rats, deoxycoticosterone acetate (DOCA) salt induces a decrease in the activity of the renin-angiotensin system but does not change the gene expression of NOS. Inducible and neural NOS gene expression are less prominent in SBH/y than in SBN/y, independent of DOCA-salt administration, suggesting that the NO system may contribute in part to the salt resistance of SBN/y (69). However, the genotypes of NOS are not related to human essential hypertension (70). 


\section{References}

1) Rapp JP, Wang SM, Dene H. A genetic polymorphism in the renin gene of Dahl rats cosegregates with blood pressure. Science 243: 542-544, 1989.

2) Kaiser M, Vincent M, Kenyon CJ, et al. Analysis of phenotypic consequences of renin gene polymorphism in Lyon rats. J Hypertens 15: 365372, 1997.

3) Bohlender J, Fukamizu A, Lippoldt A, et al. High human renin hypertension in transgenic rats. Hypertension 29: 428-434, 1997.

4) Kim HS, Krege JH, Kluckman KD, et al. Genetic control of blood pressure and the angiotensinogen locus. Proc Natl Acad Sci USA 92: 2735$2739,1995$.

5) Lodwick D, Kaiser MA, Harris J, Cumin F, Vincent M, Samani NJ. Analysis of the role of angiotensinogen in spontaneous hypertension. Hypertension 25: 1245-5121, 1995.

6) Tamura K, Umemura S, Nyui N, et al. Tissue-specific regulation of angiotensinogen gene expression in spontaneously hypertensive rats. Hypertension 27: 1216-1223, 1996.

7) Tomita N, Morishita R, Higaki J, et al. Transient decrease in high blood pressure by in vivo transfer of antisense oligodeoxynucleotides against rat angiotensinogen. Hypertension 26: 131-136, 1995.

8) Jeunemaitre X, Soubrier F, Kotelevtsev YW, et al. Molecular basis of human hypertension: role of angiotensinogen. Cell 71: 169-180, 1992.

9) Kamitani A, Rakugi H, Higaki J, et al. Association analysis of a polymorphism of the angiotensinogen gene with essential hypertension in Japanese. J Hum Hypertens 8: 521-524, 1994.

10) Barley J, Blackwood A, Sagnella G, Markandu N, MacGregor G, Carter N. Angiotensinogen Met235 $\rightarrow$ Thr polymorphism in a London normotensive and hypertensive black and white population. J Hum Hypertens 8: 639-640, 1994.

11) Caulfield $M$, Lavender $P$, Farrall $M$, et al. Linkage of the angiotensinogen gene to essential hypertension. N Engl J Med 330: 1629-1633, 1994.

12) Jacob HJ, Lindpaintner $K$, Lincoln SE, et al. Genetic mapping of a gene causing hypertension in the stroke-prone spontaneously hypertensive rat. Cell 67: 213-224, 1991.

13) Hilbert $P$, Lindpaintner $K$, Beckmann JS, et al. Chromosomal mapping of two genetic loci associated with blood-pressure regulation in hereditary hypertensive rats. Nature 353: 521-529, 1991.

14) Koike G, Krieger JE, Jacob HJ, Mukoyama M, Pratt RE, Dzau VJ. Angiotensin converting enzyme and genetic hypertension cloning rat cDNAs and characterization of the enzyme. Biochem Biophys Res Commun 198: 380-386, 1994.

15) Kreutz R, Hubner N, Ganten D, Lindpaintner K. Genetic linkage of the ACE gene to plasma angiotensin-converting enzyme activity but not to blood pressure. A quantitative trait locus confers identical complex phenotypes in human and rat hypertension. Circulation 92: 2381-2384, 1995.

16) Kreutz R, Hubner N, James MR, et al. Dissection of a quantitative trait locus for genetic hypertension on rat chromosome 10. Proc Natl Acad Sci USA 92: 8778-8782, 1995.

17) Rigat B, Hubert C, Alhenc-Gelas F, Cambien F, Corvol P, Soubrier F. An insertion/deletion polymorphism in the angiotensin I converting enzyme gene accounting for half the variance of serum enzyme levels. J Clin Invest 86: 1343-1346, 1990.

18) Jeunemaitre X, Lifton RP, Hunt SC, Williams RR, Lalouel JM. Absence of linkage between the angiotensin converting enzyme locus and human essential hypertension. Nat Genet 1: 72-75, 1992.

19) Ishigami $T$, Iwamoto $T$, Tamura $K$, et al. Angiotensin I converting enzyme (ACE) gene polymorphism and essential hypertension in Japan. Ethnic difference of ACE genotype. Am J Hypertens 8: 95-97, 1995.

20) Johnson AG, Simons LA, Friedlander Y, Simons J, Davis DR, MaCallum J. I/D polymorphism of the angiotensin-converting enzyme gene does not predict isolated systolic or diastolic hypertension in the elderly. J Hum Hypertens 10: 167-169, 1996.

21) Zee RY, Lou YK, Griffiths LR, Morris BJ. Association of a polymor- phism of the angiotensin I-converting enzyme gene with essential hypertension. Biochem Biophys Res Commun 184: 9-15, 1992.

22) Abbud ZA, Wilson AC, Cosgrove NM, Kostis JB. Angiotensin-converting enzyme gene polymorphism in systemic hypertension. Am J Cardiol 81: 244-246, 1998.

23) Vasku A, Soucek M, Znojil V, et al. Angiotensin I-converting enzyme and angiotensinogen gene interaction and prediction of essential hypertension. Kidney Int 53: 1479-1482, 1998.

24) Hiraga $H$, Oshima $T$, Watanabe $M$, et al. Angiotensin I-converting enzyme gene polymorphism and salt sensitivity in essential hypertension. Hypertension 27: 569-572, 1996.

25) Ito M, Oliverio MI, Mannon PJ, et al. Regulation of blood pressure by the type 1A angiotensin II receptor gene. Proc Natl Acad Sci USA 92: 3521$3525,1995$.

26) Iyer SN, Lu D, Katovich MJ, Raizada MK. Chronic control of high blood pressure in the spontaneously hypertensive rat by delivery of angiotensin type 1 receptor antisense. Proc Natl Acad Sci USA 93: 9960-9965, 1996.

27) Bonnardeaux A, Davies E. Jeunemaitre $X$, et al. Angiotensin II type 1 receptor gene polymorphisms in human essential hypertension. Hypertension 24: 63-69, 1994.

28) Castellano M, Muiesan ML, Beschi M, et al. Angiotensin II type 1 receptor $\mathrm{A} / \mathrm{C} 1166$ polymorphism. Relationships with blood pressure and cardiovascular structure. Hypertension 28: 1076-1080, 1996.

29) Schmidt S, Beige J, Walla-Friedel M, Michel MC, Sharma AM, Ritz E. A polymorphism in the gene for the angiotensin II type 1 receptor is not associated with hypertension. J Hypertens 15: 1385-1388, 1997.

30) Takami S, Katsuya T, Rakugi H, et al. Angiotensin II type 1 receptor gene polymorphism is associated with increase of left ventricular mass but not with hypertension. Am J Hypertens 11: 316-321, 1998.

31) Iwai $\mathrm{N}$, Inagami $\mathrm{T}$. Identification of a candidate gene responsible for the high blood pressure of spontaneously hypertensive rats. J Hypertens 10: 1155-1157, 1992.

32) Lindpaintner $K$, Hilbert $P$, Ganten $D$, Nadal-Ginard $B$, Inagami $T$, Iwai $N$. Molecular genetics of the SA-gene: cosegregation with hypertension and mapping to rat Chromosome 1. J Hypertens 11: 19-23, 1993.

33) Patel HR, Thiara AS, West KP, Lodwick D, Samani NJ. Increased expression of the SA gene in the kidney of the spontaneously hypertensive rat is localized to the proximal tubule. J Hypertens 12: 1347-1352, 1994.

34) Yang T, Hassan SA, Singh I, et al. SA gene expression in the proximal tubule of normotensive and hypertensive rats. Hypertension 27: 541-551, 1996.

35) Huang H, Pravenec M, Wang JM, et al. Mapping and sequence analysis of the gene encoding the beta subunit of the epithelial sodium channel in experimental models of hypertension. J Hypertens 13: 1247-1251, 1995.

36) Iwai N, Ohmichi N, Hanai K, Nakamura Y, Kinoshita M. Human SA gene locus as a candidate locus for essential hypertension. Hypertension 23: 375-380, 1994.

37) Zee RY, Stephen AL, Iwai N, Morris BJ. Association analyses of S(A) gene variant in essential hypertensives. Am J Hypertens 10: 235-242, 1997.

38) Melzi ML, Syren ML, Assael BM, Sereni F, Aperia A. Increased renal tubular Na-K-ATPase activity in Milan hypertensive rats in the prehypertensive period. Pediatr Nephrol 5: 700-703, 1991.

39) Bianchi G, Tripodi G, Casari G, et al. Two point mutations within the adducin gene are involved in blood pressure variation. Proc Natl Acad Sci USA 91: 3999-4003, 1994.

40) Tripodi G, Voltorta F, Torielli L, et al. Hypertension associated pointmutations in the adducin alpha and beta subunits affect actin cytoskeleton and ion transport. J Clin Invest 97: 2815-2822, 1996.

41) Cusi D, Barlassina C, Azzani T, et al. Polymorphisms of alpha-adducin and salt sensitivity in patients with essential hypertension. Lancet 349: 1353-1357, 1997.

42) Kato N, Sugiyama T, Nabika T, et al. Lack of association between the alpha-adducin locus and essential hypertension in the Japanese population. Hypertension 31: 730-733, 1998.

43) Kreutz R, Struk B, Rubattu S, et al. Role of the alpha-, beta-, and gammasubunits of epithelial sodium channel in a model of polygenic hyperten- 


\section{SATOH et al}

sion. Hypertension 29: 131-136, 1997.

44) Shimkets RA, Warnock DG, Bositis CM, et al. Liddle's syndrome: Heritable human hypertension caused by mutations in the $\beta$ subunit of the epithelial sodium channel. Cell 79: 407-414, 1994.

45) Schild L, Canessa CM, Shimkets RA, Gautschi I, Lifton RP, Rossier BC. A mutation in the epithelial sodium channel causing Liddle's disease increases channel activity in Xenopus laevis oocyte expression system. Proc Natl Acad Sci USA 92: 5699-5703, 1995.

46) Hansson JH, Nelson-Williams C, Suzuki H, et al. Hypertension caused by a truncated epithelial sodium channel gamma subunit: genetic heterogeneity of Liddle's syndrome. Nat Genet 11: 76-80, 1995.

47) Jose PA, Eisner GM, Drago J, Carey RM, Felder RA. Dopamine receptor signaling defects in spontaneous hypertension. Am J Hypertens 9: 400405, 1996.

48) Albrecht FE, Drago J, Felder RA, et al. Role of the D1A dopamine receptor in the pathogenesis of genetic hypertension. J Clin Invest 97: 22832288, 1996.

49) Gill JR Jr, Grossman E, Goldstein DS. High urinary dopa and low urinary dopamine-to-dopa ratio in salt-sensitive hypertension. Hypertension 18: 614-621, 1991.

50) Rudberg S, Lemne C, Persson B, Krekula A, de Faire U, Aperia A. The dopaminuric response to high salt diet in insulin-dependent diabetes mellitus and family history of hypertension. Pediatr Nephrol 11: 169-173, 1997.

51) Ferrandi M, Minotti E, Salardi S, Florio M, Bianchi G, Ferrari P. Ouabainlike factor in Milan hypertensive rats. Am J Physiol 263: F739F748, 1992.

52) Blaustein MP. Endogenous ouabain: role in the pathogenesis of hypertension. Kidney Int 49: 1748-1753, 1996.

53) Rayson BM. Na ${ }^{+} / \mathrm{K}^{+}$-ATPase regulation in Dahl salt-sensitive and saltresistant rats. J Biol Chem 263: 11056-11058, 1998.

54) Ferrandi M, Manunta P, Balzan S, Hamlyn JM, Bianchi G, Ferrari P. Ouabain-like factor quantification in mammalian tissues and plasma: comparison of two independent assays. Hypertension 30: 886-896, 1997.

55) Iwaoka $T$, Umeda $T$, Miura $F$, et al. Renal sodium handling and sodium transport inhibitor in salt-sensitive essential hypertension. J Hypertens 9: 49-54, 1991.

56) Stec DE, Deng AY, Rapp JP, Roman RJ. Cytochrome P4504A genotypes cosegregates with hypertension in Dahl S rats. Hypertension 27: 564$568,1996$.
57) Ma YH, Schwartzman ML, Roman RJ. Altered renal P-450 metabolism of arachidonic acid in Dahl salt-sensitive rats. Am J Physiol 267: R579R589, 1994.

58) Herrera VL, Ruiz-Opazo N. Alteration of alpha $1 \mathrm{Na}^{+}, \mathrm{K}^{+}$-ATPase ${ }^{86} \mathrm{Rb}^{+}$ influx by a single amino acid substitution. Science 249: 1023-1026, 1990.

59) Deng AY, Dene H, Pravenec M, Rapp JP. Genetic mapping of two new blood pressure quantitative trait loci in the rat by genotyping endothelin system genes. J Clin Invest 93: 2701-2709, 1994.

60) Cicila GT, Rapp JP, Bloch KD, et al. Cosegregation of the endothelin-3 locus with blood pressure and relative heart weight in inbred Dahl rats. J Hypertens 12: 643-651, 1994.

61) Disashi $T$, Nonoguchi $H$, Iwaoka $T$, et al. Endothelin converting enzyme1 gene expression in the kidney of spontaneously hypertensive rats. Hypertension 30: 1591-1597, 1997.

62) Gellai M, DeWolf R, Pullen M, Nambi P. Distribution and functional role of renal ET receptor subtypes in normotensive and hypertensive rats. Kidney Int 46: 1287-1294, 1994.

63) John SW, Krege JH, Oliver PM, et al. Genetic decreases in atrial natriuretic peptide and salt-sensitive hypertension. Science 267: 679-681, 1995.

64) Melo LG, Veress AT, Chong CK, Pang SC, Flynn TG, Sonnenberg H. Salt-sensitive hypertension in ANP knockout mice: potential role of abnormal plasma renin activity. Am J Physiol 274: R255-R261, 1998.

65) Lopez MJ, Wong SK, Kishimoto I, et al. Salt-resistant hypertension in mice lacking the guanylyl cyclase-A receptor for atrial natriuretic peptide. Nature 378: 65-68, 1995.

66) Rutledge DR, Sun Y, Ross EA. Polymorphisms within the atrial natriuretic peptide gene in essential hypertension. J Hypertens 13: 953-955, 1995.

67) Deng AY, Rapp JP. Locus for the inducible, but not a constitutive, nitric oxide synthase cosegrerates with blood pressure in the Dahl salt-sensitive rat. J Clin Invest 95: 2170-2177, 1995.

68) Shesely EG, Maeda N, Kim HS, et al. Elavated blood pressure in mice lacking endothelial nitric oxide synthase. Proc Natl Acad Sci USA 93: 13176-13181, 1996.

69) Lippoldt A, Gross V, Schneider K, et al. Nitric oxide synthase and reninangiotensin system gene expression in salt-sensitive and salt-resistent Sabra rats. Hypertension 30: 409-415, 1997.

70) Friend LR, Morris BJ, Gaffney PT, Griffiths LR. Examination of the role of nitric oxide synthase and renal kallikrein as candidate genes for essential hypertension. Clin Exp Pharmacol Physiol 23: 564-566, 1996. 